\title{
Ecology and Human Health: Medical Technology Aspects
}

\author{
A. E. Severin ${ }^{1,2}$, L. T. Sushkova ${ }^{3 *}$, and T. E. Batotsyrenova ${ }^{3}$
}

\begin{abstract}
We present here a brief review of the lines of research presented at the section Ecology and Human Health of the XIVth Conference on Physics and Radio Electronics in Medicine and Ecology (PhREME'2020), July 1-3, 2020, held in Vladimir City.
\end{abstract}

Human health is an enduring value, which continues to increase as science and technology advance. This explains the increasing interest of scientists working in various research fields, including technological sciences, in assessing, in addition to the functional state and health, the environmental conditions in which people live. This applies in particular to pollution of atmospheric air, electromagnetic radiation, and high noise levels. There is also a multiplicity of factors associated with highly urbanized environments. All these affect human physical and mental health. Humans and nature are mutually dependent.

The human environment, especially in large cities, is a complex system of social and ecological factors affecting the urban dwellers throughout the entire life. Rapid advances in science and technology lead to rapid social changes, while changes in biological processes occur significantly slower. This leads to the onset of the so-called civilization disease. The effects of daily stress can be positive or negative. If an exposure to stress is transient, it promotes the maintenance of homeostasis and the adaptation of humans to adverse factors. On the contrary, prolonged stress leads to deterioration of human body functions. This means that prolonged stress is the pathogenetic basis of a number of diseases (neurological, cardiovascular, endocrine, etc.).

The combined effects of environmental factors on human health are generally known to be mutually increasing. Addition of each new factor increases the risk

\footnotetext{
${ }^{1}$ Peoples' Friendship University of Russia, Moscow, Russia.

${ }^{2}$ Federal Research and Clinical Center of Intensive Care Medicine and Rehabilitology, Moscow, Russia.

${ }^{3}$ Vladimir State University named after Alexander and Nikolay Stoletovs, Vladimir, Russia; E-mail: ludm@vlsu.ru

* To whom correspondence should be addressed.
}

of disease. For example, the incidence of ischemic heart disease (IHD) is significantly affected by factors such as pollution of atmospheric air (a 44\% increase in the incidence of IHD), high noise levels (20\% increase), and food products containing pesticides (residual quantities of DDT in milk, meat, and butter increase the incidence of IHD by 26\%). Simultaneous exposure to these factors almost doubles the number of people with IHD [1].

Academician of the Russian Academy of Sciences N. A. Agadzhanyan said: "Problems associated with urbanization should be solved by developing a set of interconnected social, ecological, technological, and other special measures rather than by applying hasty and ineffective solutions. In all cases, humans and the environment must be regarded as a whole" [1, p. 224].

On this basis, back in 1994 - during discussions on the organization and running of the First International Scientific Conference on Physics and Radio Electronics in Medicine and Ecology - the decision was taken to create the special section Ecology and Human Health.

At the XIVth International Scientific Conference on Physics and Radio Electronics in Medicine and Ecology (PhREME'2020), held on July 1-3, 2020 in Vladimir, the Ecology and Human Health section included presentations of more than 25 reports directly addressing problems of ecology and human health. These reports covered a quite wide spectrum of medical and biological problems - from improving methods and means for analysis of various biosignals (electroencephalogram, electrocardiogram, photocardiogram, etc.) and their prognostic value for assessing the functional state of the human body to the analysis of measures of health and the functional reserves of the body in different population groups, dominated by studies made by students. 
Reports addressing novel algorithms for analysis of various biosignals provide evidence of progress in this area of research and the transition from analysis of individual signals to simultaneous processing of multiple linked biological information streams. Thus, Kuznetsov's report, addressing the juxtaposition of electroencephalogram (EEG) and electrocardiogram (ECG) parameters, showed that addition of chaosgrams to standard EEG studies provides for overall analysis of the phase components of the EEG. Nonstationary EEG components and divergence of fractal ECG and EEG coefficients are indicators of desynchronization of heart rhythm regulation processes and, thus, predictors for the development of cardiac arrhythmias and other impairments of cardiac activity [2]. These proposals are quite realistic, as follows from a large number of studies suggesting methods for identifying ECG elements.

In particular, in Dakhva's report [3], the current scientific challenge of automating the processing and analysis of the ECG to provide early diagnosis and treatment of cardiovascular diseases (CVD) was considered. Improvement and development of electronic and computer systems and technologies make a significant contribution to clinical cardiology and promote the creation of new decision-making systems used by medical specialists. The most pronounced part of the ECG signal is the QRS complex, which is widely used for diagnosing the functional state of the cardiovascular system. A wide range of published sources (more than 40) was reviewed in [3]. It was shown that current methods for the detection, processing, and analysis of QRS complexes could be used in an automated mode. Dakhva presented a comparative analysis of ECG processing using different methods (analysis of the first and second derivatives of the ECG, methods based on digital filters, a latent Markov model, the PanTompkins algorithm, the Hilbert-Huang and wavelet transforms, as well as the fast Fourier transform), each with its own advantages and drawbacks. This prepared the soil for comparative analysis of biological signals from the point of view of their information value for assessing the functional state of the body and determining, on this basis, the general functional reserves of the body overall or of separate functional systems, leading thereby to a progress in our understanding of physiological processes and formalization of their description.

An illustration of this is the report made by Tomchuk [4], which presented a "geometrical" approach to diagnosis of the functional state of the body. This approach involves presentation of data from different functional tests in normalized form. The relative values of particular indicators range from 0 to 1.0 . During the study, biomedical parameters were recorded on completion of each test stage. The test stages differed in loading intensities. The author took the view that the area of the polygon obtained for each test served as an integral measure of functional reserves [4]. This method is akin to the cardiorhythmogram "phase portrait" technique developed by Fleishman, which also involves analysis of the geometrical characteristics of a figure obtained on a surface by sequential recording of two parameters (cardiac cycle duration and difference between neighboring cardiac cycles) [5]. It can be expected that these approaches will subsequently lead to the formation of multidimensional spaces providing quite complete information on the functional state and reserves of the body.

Along with analysis of different biological signals, studies were presented in which questions of controlling various technical systems substituting for lost body functions were addressed; for example, control of devices for mechanical pulmonary ventilation, as well as development of dynamic illumination for retention of normal circadian biological rhythms, which are known to depend on illumination levels.

The report "New approaches to controlling the parameters of mechanical pulmonary ventilation" [6] is of interest because of its relevance in relation to the COVID-19 pandemic. A high proportion of COVID-19 patients are kept on mechanical pulmonary ventilation (MPV) for prolonged periods. It has been shown in [6] that the use of MPV devices requires further improvement. Available MPV devices do not use the physiological principles of respiration: inspiration is mediated by pumping air into the lungs at elevated intrapulmonary pressure and decreased venous return of blood to the heart, while expiration, conversely, is at reduced intrapulmonary pressure and elevated blood flow to the heart. These conditions impair the physiological mechanism synchronizing cardiac activity and respiration. This produces the complications associated with prolonged MPV. This problem has been widely covered in the literature on anesthesiology. However, computer control of MPV devices is thus far conducted exclusively in terms of parameters associated with respiration, i.e., inspiratory volume, respiratory frequency, pressure in the main gas lines of the MPV, and hemoglobin oxygen saturation. However, assessment of these parameters is not sufficient for preventing MPV complications. Analysis of innovations in the design of MPV devices shows that mechanical ventilation becomes "physiologized" and takes account of the physiological mechanisms of respiration. The report made at the PhREME'2020 conference provided grounds for changes in the control system of MPV devices, in which the control signals, along with respiratory and the oxygen regime parameters, include hemody- 
namic parameters (in particular, heart rate variability) to minimize the adverse consequences of prolonged MPV.

Report [7], from Badalyan and Kolesnik, was of special interest. It addressed the development of a biodynamic illumination system intended to maintain natural circadian biological rhythms of the nervous system activity in various living and work spaces. The illumination algorithm suggested by the authors corresponds to the dynamics of natural insolation at different times of day.

In this regard, it should be noted that the evolution of various medical technical systems follows the path of "physiologization", i.e., developing devices whose operation preserves the main physiological regulation principles and whose operation depends on the body's physiological reactions.

A significant number of studies focused on issues in the health of different population groups. Thus, young scientist Blokhin's report, "Dynamic observations of the functional state of first-year students" [8], presented the results of longitudinal investigations of the functional state of students at Vladimir State University over a 10year period - from 2008 to 2017 inclusive. Young men and women showed a clear trend to increased levels of autonomic regulatory tension over this period. These data provide evidence of a vital need to improve existing and develop new sets of physical, health-giving, and other recreational activities directed at improving the state of health and increasing the level of the body's functional reserves in students. The key here is the work of Filatov and Filatova, Budyk, Litvinova, and others [9-15], which analyzed different aspects of health and disease in different population groups. The report by Stekhin et al. "Exchange electronic interactions as the basis of the factor maintaining stability in the body's homeostasis" [16] is of particular interest. It considered theoretical questions linked with the balance of energy processes in the body, which may provide the molecular basis and a pathogenetic component of the formation of different physiological and pathological states.

Reports in the framework of the section Ecology and Human Health also addressed the problems of assessing external factors affecting sportsmen, using current technologies to evaluate the effectiveness and level of training, and introducing different means and techniques of physical exercise to increase the level of population health [4, $17,18]$.

Thus, the report "Stochastic and chaotic evaluation of gait cadence: Biomechanical, age, and sex associations" [18] presented the results of studies of energy dissipation by humans at different gait tempos. Walking can be a health-promoting physical exercise. This raises the question of selecting the appropriate gait tempo depend- ing on the functional state of the body. The authors used the following as initial data:

- walking intensity, which was classified in terms of the level of energy expenditure as: low-intensity, i.e., normal walking, with energy dissipation of less than 3 MET $\left(1 \mathrm{MET}=1.2 \mathrm{cal} / \mathrm{kg} / \mathrm{min}\right.$, or $3.5-4 \mathrm{~mL} \mathrm{O}_{2}$ consumed per min per kg body weight); moderate intensity is energy dissipation of 3-6 MET; high intensity is energy dissipation of $>6$ MET;

- gait tempo (determined by stride length) and gait rhythm (determined by stride frequency).

However, the mechanism of selection of the gait tempo and rhythm is unclear. Together, these determine gait cadence (strides per min). It is also known that on walking for more than $10 \mathrm{~min}$ without stopping, humans select gait cadence unconsciously.

Thus, the aim of the scientific study reported in [18] was to identify the patterns of energy dissipation in people of different age and sex at different gait cadences. People of young and middle age took part in the study as volunteers. The tests included walking on a treadmill at speeds of $2-7 \mathrm{~km} / \mathrm{h}$, for $5 \mathrm{~min}$ at each speed. Parameters such as oxygen consumption, respiratory rate, heart rate, and gait characteristics (full stride duration, stride length, transfer duration, and foot support time) were recorded and used to calculate the gait index (GI). Within the framework of the study, the authors developed mathematical models of the relationship between energy dissipation $(E, \mathrm{MET})$ and gait cadence (GC, strides per min).

The investigators taking part in the conference did not ignore questions of the effects of environment on the human body and the associated questions of maintaining appropriate microclimatic characteristics of living and work spaces. Thus, report [19], "Creation of artificial microclimates" suggested using a vortex generator of original design to provide optimum microclimate conditions with low air movement speeds. The resulting air vortices provided effective ventilation of the space without creating unpleasant sensations of cooling or exposure to the wind. A method and a device were proposed for creating a comfortable microclimate in locations, especially those of small volume, such as vehicle interiors, spacecraft, etc. A more detailed description of the presented method for room ventilation using a vortex generator is given by the RF patent No. 2232353 MRK F24F7/02 obtained by the authors.

The effects of microclimate conditions on the human body were analyzed by Zalata, Evstaf'eva, Astafurov, et al., in the report "Psychoemotional weather lability and weather sensitivity among adult inhabitants of the Republic of the Crimea with different states of health" [20]. The authors considered the influences of the geomagnetic context, solar radiation, atmospheric pres- 
sure, and other weather factors on the psychoemotional state of people with different functional reserves of the cardiovascular system. These studies determined the gradient of tolerance to changes in weather conditions depending on the person's state of health. The obtained results allow planning of personalized prophylactic measures in cases of sharp changes in weather conditions.

\section{Conclusions}

Discussions held in the section Ecology and Human Health demonstrated an active interest among the conference participants in the complex problem of assessment of the human body interaction with the environment and the need to identify study methods with the greatest potential for obtaining breakthrough scientific and practical results contributing to solving general theoretical problems of human health and practical questions in the diagnostic, prognostic, and recreational domains.

\section{REFERENCES}

1. Agadzhanyan, N. A. and Torshin, V. I., Human Ecology. Selected Readings [in Russian], KRUK, Moscow (1994).

2. Kuznetsov, A. A., "Analysis of electroencephalograms and rhythmograms on synchronous recording," in: Proc. XIVth Int. Sci. Conf. Physics and Radio Electronics in Medicine and Ecology (PhREME’2020), July 1-3, 2020, Vladimir-Suzdal, Vol. 2 [in Russian], pp. 312-316.

3. Dakhva, M. S., "Comparison and review of EEG processing methodologies for QRS detection tasks," in: Proc. XIVth Int. Sci. Conf. Physics and Radio Electronics in Medicine and Ecology (PhREME'2020), July 1-3, 2020, Vladimir-Suzdal, Vol. 2 [in Russian], pp. 365-373.

4. Tomchuk, A. A., "Methods of processing biomedical signals for assessment of physiological reserves," in: Proc. XIVth Int. Sci. Conf. Physics and Radio Electronics in Medicine and Ecology (PhREME'2020), July 1-3, 2020, Vladimir-Suzdal, Vol. 2 [in Russian], pp. 324-327.

5. Fleishman, A. N., "Slow cardiac rhythm oscillations and the phenomenon of nonlinear dynamics: Classification of phase portraits of measures of energy, spectral, and detrended analyses," in: Proc. 3rd All-Russian Symposium Slow Oscillatory Processes in the Human Body. Theoretical and Applied Aspects of Nonlinear Dynamics, Chaos, and Fractals in Physiology and Medicine, May 21-25, 2001 [in Russian], Novokuznetsk (2001), pp. 49-61.

6. Severin, A. E., Petrova, M. V., Sushkova, L. T., Semenov, Yu. N., Kramm, M. N., and Shalimova, E. V., "New approaches to controlling the parameters of mechanical pulmonary ventilation," in: Proc. XIVth Int. Sci. Conf. Physics and Radio Electronics in Medicine and Ecology (PhREME'2020), July 1-3, 2020, Vladimir-Suzdal, Vol. 2 [in Russian], pp. 318-320.

7. Badalyan, N. P., Kolesnik, G. P., and Belyakova, D. A., "Biodynamic illumination as a function of the control of state in humans," in: Proc. XIVth Int. Sci. Conf. Physics and Radio Electronics in Medicine and Ecology (PhREME'2020), July 1-3, 2020, Vladimir-Suzdal, Vol. 2 [in Russian], pp. 377-382.
8. Blokhin, M. M. and Batotsyrenova, T. E., "Dynamic observations of the functional state of first-year students," in: Proc. XIVth Int. Sci. Conf. Physics and Radio Electronics in Medicine and Ecology (PhREME’2020), July 1-3, 2020, Vladimir-Suzdal, Vol. 2 [in Russian], pp. 316-318.

9. Filatov, V. O. and Filatova, O. V., "Empirical studies of the features of subjective wellbeing in students in technical disciplines," in: Proc. XIVth Int. Sci. Conf. Physics and Radio Electronics in Medicine and Ecology (PhREME'2020), July 1-3, 2020, Vladimir-Suzdal, Vol. 2 [in Russian], pp. 349-353.

10. Budyka, E. V., "Interdisciplinary studies of health: An approach to neuropsychology of individual differences," in: Proc. XIVth Int. Sci. Conf. Physics and Radio Electronics in Medicine and Ecology (PhREME'2020), July 1-3, 2020, Vladimir-Suzdal, Vol. 2 [in Russian], pp. 334-336.

11. Litvinova, N. Yu., "Psychological and psychosomatic aspects of resistance to infectious diseases of the upper respiratory tract," in: Proc. XIVth Int. Sci. Conf. Physics and Radio Electronics in Medicine and Ecology (PhREME'2020), July 1-3, 2020, Vladimir-Suzdal, Vol. 2 [in Russian], pp. 343-347.

12. Usenkova, E. V., "The speech therapy vector in the diagnosis of dysphagia in patients with CNS diseases," in: Proc. XIVth Int. Sci. Conf. Physics and Radio Electronics in Medicine and Ecology (PhREME'2020), July 1-3, 2020, Vladimir-Suzdal, Vol. 2 [in Russian], pp. 347-349.

13. Shamanin, N. V., "Behavioral coping strategies in patients with oncological diseases," in: Proc. XIVth Int. Sci. Conf. Physics and Radio Electronics in Medicine and Ecology (PhREME'2020), July 1-3, 2020, Vladimir-Suzdal, Vol. 2 [in Russian], pp. 362-365.

14. Beznosova, V. E., Apollonova, I. A., and Nikolaev, A. P., "Determination of levels of psychological stress on prolonged exposure to various factors," in: Proc. XIVth Int. Sci. Conf. Physics and Radio Electronics in Medicine and Ecology (PhREME'2020), July 1-3, 2020, Vladimir-Suzdal, Vol. 2 [in Russian], pp. 382-384.

15. Bogatov, N. M., Bogatova, A. N., and Sukhikh, S. A., "Effects of psychophysiological processes on the state of biologically active points," in: Proc. XIVth Int. Sci. Conf. Physics and Radio Electronics in Medicine and Ecology (PhREME'2020), July 1-3, 2020, Vladimir-Suzdal, Vol. 2 [in Russian], pp. 384-388.

16. Stekhin, A. A., P'yanzina, I. P., Yakovleva, G. V., Minin, I. V., and Karasev, A. K., "Exchange electronic interactions as the basis of the factor maintaining stability in the body's homeostasis," in: Proc. XIVth Int. Sci. Conf. Physics and Radio Electronics in Medicine and Ecology (PhREME'2020), July 1-3, 2020, Vladimir-Suzdal, Vol. 2 [in Russian], pp. 331-334.

17. Filatov, D. O. and Zobkov, V. A., "The competitive environment and emotional state of fighters in the Greco-Roman style," in: Proc. XIVth Int. Sci. Conf. Physics and Radio Electronics in Medicine and Ecology (PhREME'2020), July 1-3, 2020, Vladimir-Suzdal, Vol. 2 [in Russian], pp. 355-358.

18. Loginov, S. I., Kintyukhin, A. S., and Snigirev, A. S., "Stochastic and chaotic evaluation of gait cadence: Biomechanical, age, and sex associations," in: Proc. XIVth Int. Sci. Conf. Physics and Radio Electronics in Medicine and Ecology (PhREME'2020), July 1-3, 2020, Vladimir-Suzdal, Vol. 2 [in Russian], pp. 327-331.

19. Olenev, E. A. and Sushkova, L. T., "Creation of artificial microclimates," in: Proc. XIVth Int. Sci. Conf. Physics and Radio Electronics in Medicine and Ecology (PhREME'2020), July 1-3, 2020, Vladimir-Suzdal, Vol. 2 [in Russian], pp. 388-391.

20. Zalata, O. A., Evstaf'eva, E. V., Astafurov, D. D., Slyusarenko, A. A., and Prasolov, N. S., "Psychoemotional weather lability and weather sensitivity among adult inhabitants of the Republic of the Crimea with different states of health,” in: Proc. XIVth Int. Sci. Conf. Physics and Radio Electronics in Medicine and Ecology (PhREME'2020), July 1-3, 2020, Vladimir-Suzdal, Vol. 2 [in Russian], pp. 320-324. 